
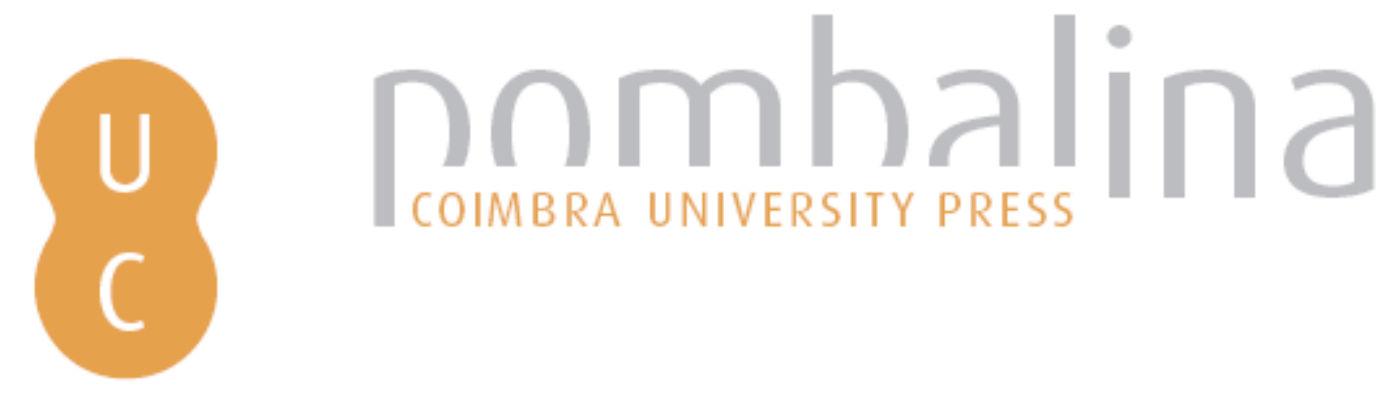

Da literacia à fluência: como avaliar o nível de proficiência digital de professores?

Autor(es): $\quad$ Dias-Trindade, Sara; Moreira, J. António

Publicado por: Imprensa da Universidade de Coimbra

URL

persistente: URI:http://hdl.handle.net/10316.2/47411

DOI: $\quad$ DOl:https://doi.org/10.14195/978-989-26-1772-5_3

Accessed : $\quad$ 26-Apr-2023 11:20:57

A navegação consulta e descarregamento dos títulos inseridos nas Bibliotecas Digitais UC Digitalis, UC Pombalina e UC Impactum, pressupõem a aceitação plena e sem reservas dos Termos e Condições de Uso destas Bibliotecas Digitais, disponíveis em https://digitalis.uc.pt/pt-pt/termos.

Conforme exposto nos referidos Termos e Condições de Uso, o descarregamento de títulos de acesso restrito requer uma licença válida de autorização devendo o utilizador aceder ao(s) documento(s) a partir de um endereço de IP da instituição detentora da supramencionada licença.

Ao utilizador é apenas permitido o descarregamento para uso pessoal, pelo que o emprego do(s) título(s) descarregado(s) para outro fim, designadamente comercial, carece de autorização do respetivo autor ou editor da obra.

Na medida em que todas as obras da UC Digitalis se encontram protegidas pelo Código do Direito de Autor e Direitos Conexos e demais legislação aplicável, toda a cópia, parcial ou total, deste documento, nos casos em que é legalmente admitida, deverá conter ou fazer-se acompanhar por este aviso.

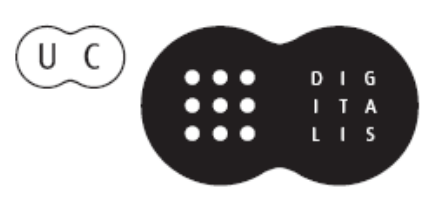




\section{EDUCAÇÃO E}

\section{HUMANIDADES}

IMPRENSA DA

UNIVERSIDADE

DE COIMBRA

COIMBRA

UNIVERSITY

DIGITAIS

APRENDIZAGENS,

TECNOLOGIAS E

CIBERCULTURA

SARA DIAS-TRINDADE DANIEL MILL

(ORGS.)

की
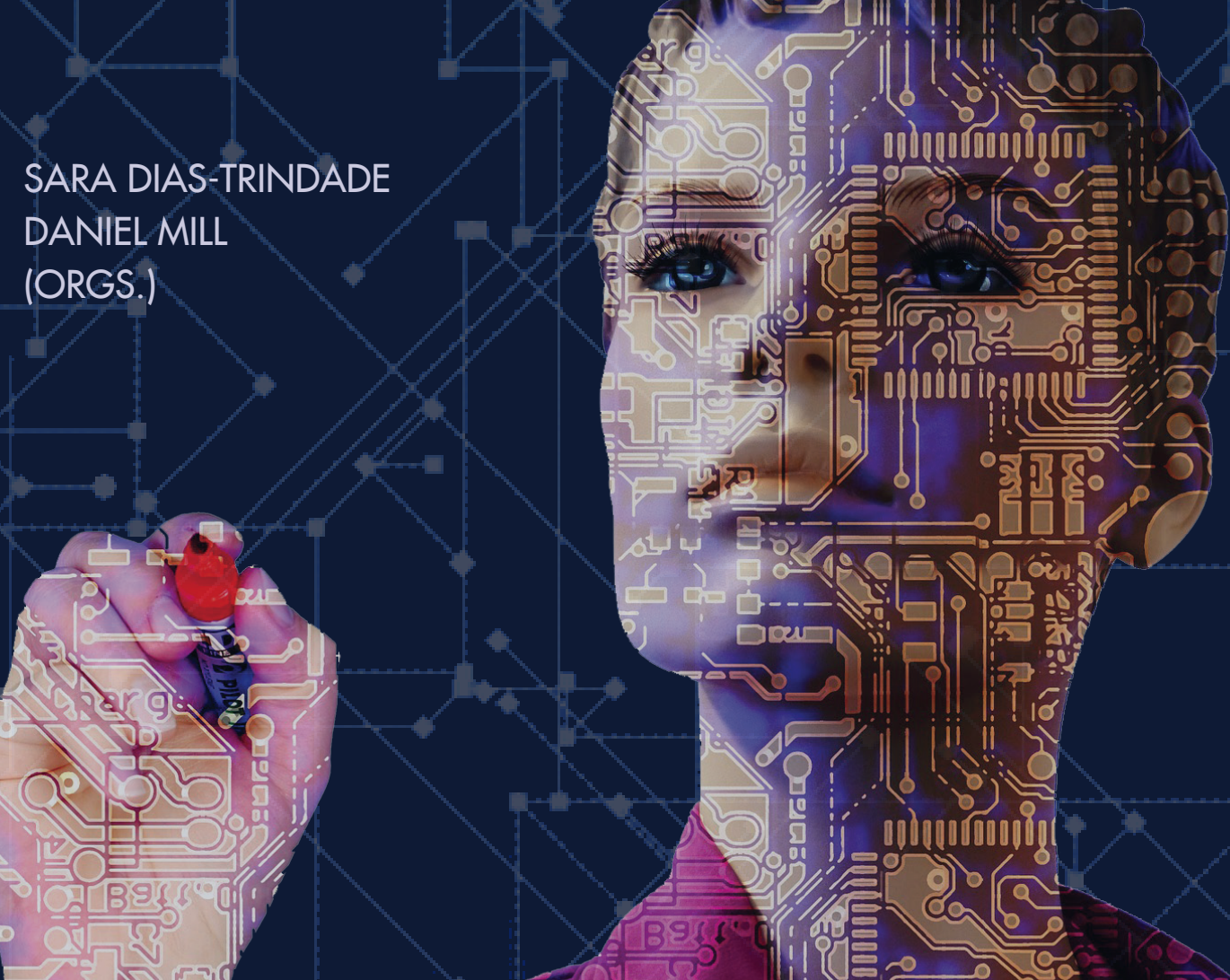
SARA DIAS-TRINDADE

Departamento de História, Estudos Europeus, Arqueologia e Artes - Faculdade de Letras da Universidade de Coimbra

Centro de Estudos Interdisciplinares do Século $X X$ - Universidade de Coimbra

ORCID: https://orcid.org/0000-0002-5927-3957

\section{J. ANTÓNIO MOREIRA}

Departamento de Educação e Ensino a Distância - Universidade Aberta

Centro de Estudos Interdisciplinares do Século XX - Universidade de Coimbra

ORCID: https://orcid.org/0000-0003-0147-0592

\section{DA LITERACIA À FLUENCIA: COMO AVALIAR O NíVEL DE PROFICIENCIA DIGITAL DE PROFESSORES?}

FROM LITERACY TO FLUENCY: HOW TO ASSESS THE LEVEL OF DIGITAL PROFICIENCY OF TEACHERS?

RESUMO: Vive-se hoje uma Era onde o real e o virtual se confundem cada vez mais, mas também onde ainda existe um longo caminho a percorrer no que diz respeito à integração das tecnologias digitais em ambientes educativos. Na verdade, não é o facto de que se nasce já em pleno mundo digital que garante, a priori, uma competência para usar, no ensino ou na aprendizagem, ferramentas digitais. Aos estudantes, torna-se necessário compreender como transportar o uso quotidiano que fazem das tecnologias digitais para as suas aprendizagens, aos docentes torna-se fundamental perceber como usar essas mesmas tecnologias para criar cenários sustentáveis de aprendizagem onde as estratégias de ensino fazem uso do digital para criar ambientes motivadores e criativos. Neste contexto, o questionário elaborado pelo EU Science Hub, DigCompEduCheckIn, vem permitir aos docentes perceber quais as suas competências ao nível do uso educativo das tecnologias digitais mas, mais ainda, sugere novas estratégias para ultrapassar as dificuldades existentes e alcançar aquilo que no nosso entendimento poderá ser uma verdadeira fluência digital, ou seja, não só fazer uso das tecnologias digitais mas compreender quando é que esse uso é efetivamente rentável para atingir os objetivos desejados. Neste texto apresentamos um projeto que faz uso desse mesmo questionário para, a partir dos resultados que vierem a ser obtidos em função das respostas dos professores, definir estratégias que possam ser aplicadas quer na formação contínua de professores quer mesmo na própria formação inicial.

Palavras-chave: Tecnologias Digitais; Fluência Digital; Competências Digitais; Formação Docente. 
ABSTRACT: There is an age where the real and the virtual are becoming more and more confused, but also where there is still a long way to go when it comes to integrating digital technologies into educational environments. In fact, it is not the fact that one is already born in the digital world that guarantees, a priori, a competence to use, in teaching or learning, digital tools. For students, it becomes necessary to understand how to transport the daily use that they make of the digital technologies for their learning, for teachers, it becomes fundamental to perceive how to use those same technologies to create sustainable learning scenarios where the teaching strategies make use of digital to create motivating and creative environments. In this context, the questionnaire prepared by the EU Science Hub, DigCompEduCheckIn, allows teachers to understand their competences in the educational use of digital technologies, but even more, it suggests new strategies to overcome the existing difficulties and achieve what in our understanding it can be a true digital fluency, that is, not only make use of digital technologies but understand when this use is effectively profitable to achieve the desired goals. In this text, we present a project that uses the same questionnaire to define strategies that can be applied in the continuous training of teachers and even in the initial formation.

Keywords: Digital Technologies; Digital Fluency; Digital Competencies; Teacher Training.

\section{Introdução}

Com o desenvolvimento das tecnologias digitais de informação e comunicação (TDIC), a Educação encontrou mecanismos para desenvolver novos ambientes de aprendizagem, procurando recolher o que de melhor as TDIC podiam dar ao desenvolvimento do processo educativo, e adaptar-se aos novos estudantes, nômades digitais, hiperconectados, ubíquos e que se movimentam de forma fluida e híbrida no ciberespaço.

Em função desta questão, a temática da literacia digital tornou-se quase incontornável em todos os discursos sobre tecnologias aplicadas à educação, muito se argumentando a propósito da validade ou não destes recursos na criação de ambientes de aprendizagem enriquecidos digitalmente. Porém, a questão coloca-se, cada vez mais, não só na utilização das TDIC e na existência de uma literacia digital, mas, mais do que isso, em perceber de que forma se pode utilizar essa tecnologia de forma a atingir os objetivos desejados, ou seja, o que fazer para ser "fluente digital". De facto, tanto educadores como estudantes devem procurar técnica e pedagogicamente aprender a trabalhar em plataformas digitais e "aprender a usar" diferentes ferramentas tecnológi- 
cas, sobretudo as associadas aos dispositivos móveis que fazem cada vez mais parte do quotidiano dos estudantes.

Considera-se também relevante perceber de que forma se podem articular currículos e competências, para dar resposta aos novos desafios com que se deparam as Escolas e assim contribuir para o desenvolvimento de um novo perfil de aluno, adequado às necessidades dos mercados de trabalho do século 21. Nesse contexto, assume-se como fundamental encontrar estratégias que proporcionem o desenvolvimento de uma verdadeira educação inclusiva, e, para além de procurar a promoção das competências para o século 21 (WEF, 2015), entende-se desejável ainda assegurar uma educação de qualidade, promovendo oportunidades de aprendizagem ao longo da vida, no quadro dos objetivos da Agenda 2030 das Nações Unidas (UN, 2015).

Assim, nesta simbiose entre tecnologia, pedagogias e aprendizagens, dever-se-ão criar cenários de aprendizagem, digitais, híbridos, pervasivos e em constante adaptação aos interesses e às necessidades quer dos estudantes, quer dos seus docentes.

Neste texto, apresentam-se as diferenças entre literacia e fluência digital, em particular de que forma elas configuram etapas para o desenvolvimento da proficiência digital para a utilização da tecnologia, nomeadamente, no que diz respeito ao contexto educativo.

Para além disso, é importante ainda perceber que os professores e os estudantes podem utilizar os seus próprios conhecimentos, quer no campo tecnológico, quer no científico, para trabalhar em rede e, desta forma, criar ambientes educativos inovadores nos quais as competências digitais podem conduzir a uma utilização eficaz e criteriosa da tecnologia digital em função dos objetivos a atingir, representando, precisamente, o que é ser fluente digital (Briggs; Makice, 2012).

Pretende-se, ainda, apresentar um instrumento de trabalho desenvolvido pelo EU Science Hub (Serviço de Ciência e Conhecimento da Comissão Europeia) que procura fazer uma avaliação das competências de professores no campo digital, para, a posteriori, atuar em função das necessidades dos atores do processo educativo, de forma a, efetivamente, conseguir usar a tecnologia digital para desenvolver cenários sustentáveis de inovação pedagógica. 


\section{Tecnologias digitais na educação}

O mundo evoluiu, a sociedade já não é a mesma. As possibilidades geradas pelas tecnologias vieram modificar completamente a forma como se vive, como as pessoas se relacionam e como o conhecimento é alcançado. Neste contexto, torna-se cada vez mais difícil distinguir o que é real e o que é virtual; o que é humano, máquina ou natureza (Floridi, 2015). Esta reflexão é fruto de uma consciencialização de que as tecnologias digitais vieram hibridizar toda a nossa sociedade, fazendo com que deixe de fazer qualquer sentido procurar separar o que é feito online do que é offline, surgindo, pois, o termo onlife, a partir de um projeto de 2012, da União Europeia, que em 2015 deu origem à publicação The Onlife Manifesto ${ }^{1}$.

É, por isso, necessário repensar a forma como se vê a Escola e como se define o que é hoje uma pedagogia que se constrói em espaços com mais "respiração", sem barreiras nem muros físicos ou digitais, apelidada de Pedagogia 2.0 e que se assume como a arte ou a ciência de ensinar com ferramentas da web 2.0 e assenta na interseção de três elementos Ps: a Participação em comunidades de rede, a Personalização da experiência de aprendizagem e a Produtividade relacionada com a criação do conhecimento (Lee; McLoughlin, 2007).

Nesta perspetiva não há, pois, como evitar deixar que a tecnologia entre na Escola. Ela está presente no quotidiano de todos os nossos estudantes, fazendo parte integrante da sua vida. Trindade e Moreira (2017b) referem precisamente que o desafio se encontra em saber utilizar a tecnologia "para transformar a aprendizagem num ato normal do quotidiano, até mesmo fazendo com que esta nem seja sequer reconhecida como sendo aprendizagem" (p. 55).

A integração de tecnologias digitais no sistema educativo e, mais concretamente, o desenvolvimento de ecossistemas digitais de aprendizagem possibilitam uma fruição de todas as vantagens associadas às tecnologias

${ }^{1}$ Disponível em <https://link.springer.com/content/pdf/10.1007\%2F978-3-319-04093-6. pdf $>$. 
educativas, entendidas como motivadoras e propiciadoras de ambientes diversificados, híbridos, férteis e dinâmicos, fomentadores de aprendizagens cada vez mais completas (Trindade; Moreira, 2018). Nesse sentido, o desafio não está somente na integração de estratégias digitais na sala de aula, mas sim em usá-las de uma forma que permita o desenvolvimento das ditas competências emancipadoras, ou seja, que colabore no desenvolvimento de um sentimento de pertença ativa dos jovens estudantes quer na sua comunidade educativa, quer, mais tarde, no mundo do trabalho (Figueiredo, 2016).

Porém, para que esta mudança ocorra, é necessário que professores e estudantes consigam aprender a utilizar a tecnologia digital em contexto educativo de uma forma que crie cenários inovadores e sustentáveis de aprendizagem, proporcionando uma efetiva melhoria do processo educacional. Para isso, professores e estudantes precisam adaptar-se aos novos tempos e aprender a utilizar as tecnologias digitais neste contexto. O uso quotidiano da tecnologia não implica uma natural conversão da sua utilização dentro dos muros da Escola. Até porque, nestes novos contextos, a educação extravasa o espaço físico e o tempo da aula. Na verdade, fazer uso da tecnologia para ensinar ou para aprender, servir-se dela para estender a aprendizagem para ambientes informais ou não formais implica possuir competências ao nível da educação digital.

E são modelos como o Tecnological Pedagogical Content Knowledge (TPACK) (Mishra; Koehler, 2006; Koehler; Mishra, 2008) que podem contribuir para a aquisição destas competências e para o aumento da proficiência digital. Com efeito, ao identificar a natureza do conhecimento exigido para a integração da tecnologia no ensino, este modelo pode dar uma resposta muito eficaz para colmatar as lacunas identificadas ao nível da literacia digital. Com a aplicação deste referencial à prática docente, pretende-se que o professor seja capaz de tomar decisões fundamentadas no desenho das suas atividades de ensino com as tecnologias, o que, segundo Cox (2008), pressupõe: a) saber utilizar as tecnologias, b) numa dada área curricular, c) integrada numa estratégia pedagógica, d) num determinado contexto educativo, e) para promover a construção do conhecimento do estudante (Cox, 2008 apud Trindade; Moreira, 2017b). 


\section{Literacia digital versus Fluência digital}

De acordo com Beetham e Sharpe (2007), é muito importante refletir sobre as pedagogias, repensar as metodologias e as estratégias, porque, por vezes, os docentes usam diferentes tecnologias digitais sem efetivamente verificar se estas são ou não pedagogicamente efetivas.

Por esse motivo é tão importante não só saber utilizar a tecnologia digital, mas, sobretudo, saber quando e como utilizá-la pedagogicamente para melhorar a qualidade do processo de ensino-aprendizagem. Ou seja, a questão não é só saber quando usar a tecnologia, mas também saber distinguir quais as ferramentas ou quais as estratégias digitais que podem melhor ajudar a cumprir os objetivos educativos em diferentes momentos (Ozan; Kezim, 2013). Se para as novas gerações de estudantes a partilha de informação é uma realidade, então deve-se fomentar a criação de ambientes de aprendizagem colaborativos enriquecidos com as tecnologias. Como referem Schlemmer e Backes (2015, p. 305, tradução nossa), "estamos desenvolvendo a capacidade de 'pensar com' e 'a partir do' uso dessas tecnologias, construindo mundos virtuais que são, também, mundos nos quais vivemos”.

Outra questão que frequentemente se coloca é se a capacidade de acesso a um incalculável volume de informação é algo positivo ou negativo. Teremos acesso a muita informação ou a informação a mais? Como articular o acesso a intermináveis fluxos de informação com a capacidade de saber filtrar de forma crítica?

Perante estas questões, torna-se premente perceber exatamente como se pode definir alguém que consegue utilizar tecnologias digitais e rentabilizar as suas possibilidades em função dos interesses e dos objetivos a concretizar. E é aqui que se pode diferenciar aqueles que são digitalmente letrados dos que são digitalmente fluentes. De facto, a tecnologia digital permite o acesso a mais conhecimento, pode permitir a formação de redes e um trabalho muito mais colaborativo. Em ambientes educativos digitais, o "aprender" e o "aprender fazendo" complementam-se numa prática construtivista, em que o estudante pode rentabilizar os conhecimentos do seu próprio quotidiano e aprender a aplicá-los na aquisição de mais conhecimentos. Neste contexto, o professor pode ter ao seu dispor diferentes aplicativos e ferramentas que lhe 
permitem uma apresentação da informação de forma diferenciada, e o estudante pode aprender de uma forma mais customizada.

E esta ideia, na verdade, não é recente. Já em 1999, o National Research Council dos EUA indicava existirem diferenças entre aqueles que conseguiam trabalhar com ferramentas tecnológicas e os que não conseguiam:

aplicar de forma produtiva no seu trabalho e na sua vida quotidiana, de reconhecer quando as tecnologias da informação podem assistir ou impedir o alcance de um objetivo, e de continuamente ser capaz de adaptar as mudanças e os avanços nas tecnologias da informação (NRC, 1999, p. 15, tradução nossa). ${ }^{2}$

No mesmo texto, identificam-se três tipos diferentes de conhecimento apelidados pelos autores de FITness (fluency with information technology): capacidades intelectuais para utilizar as tecnologias em diferentes ambientes, complexos e sustentáveis, e que articulam plenamente com o quotidiano do cidadão; domínio de conceitos relativos à própria base a partir da qual se desenvolvem as tecnologias da informação, conceitos esses que os autores defendem que sejam compreendidos através da prática e não apenas pela leitura de documentos; competências sempre em atualização, no sentido em que o utilizador consegue usar diferentes ferramentas tecnológicas e adaptar-se à sua evolução e mesmo ao surgimento de novas ferramentas (NRC, 1999). Recentemente, Wang, Myers e Sundaram (2012) demonstraram que esta questão de FITness não está relacionada com a idade ou com o género, mas sim com outros fatores, nomeadamente com o facto de:

a relação recíproca entre o uso real e a fluência digital implica um potencial círculo virtuoso para melhorar a fluência digital de uma pessoa, e, alternativamente, isso também poderia implicar um círculo vicioso, que aprofunda a divisão digital (Wang; Myers; Sundaram, 2012, p. 10). ${ }^{3}$

2 No original: "understand information technology broadly enough to be able to apply it productively at work and in their everyday lives, to recognize when information technology would assist or impede the achievement of a goal, and to continually adapt to the changes in and advancement of information technology".

3 No original: "reciprocal relationship between actual use and digital fluency implies a potential virtuous circle to improve one's digital fluency. Alternatively, this could also imply a vicious circle, which deepens the digital divide". 
Ainda a este respeito, poderemos interligar a ideia de um ciclo vicioso que aprofunda a divisão digital através da capacidade de utilizar, ou não, a tecnologia digital de uma forma criteriosa, pensada e de forma a obter os melhores resultados para os objetivos definidos.

\section{Proposta de definição de competências digitais dos professores}

Tanto no nível nacional quanto no internacional, tem existido um crescimento da consciência de que os professores devem acompanhar a evolução tecnológica e capacitar-se ao nível das suas competências digitais. Porém, encontramos muitas vezes a perceção, por parte de muitos docentes, de que, por um lado, a formação especializada existente não acompanha as suas reais necessidades e, por outro, a burocracia escolar em que se encontram envolvidos não liberta tempo disponível para se dedicarem a uma efetiva formação continuada nesta área.

Estas perceções resultam, porém, na sua maioria, de opiniões soltas, desabafos de corredor e não tanto de estudos efetivos que comprovem o nível de proficiência digital dos professores. E é neste contexto que se tornam relevantes trabalhos como os que se encontram a ser desenvolvidos no $E U$ Science Hub, departamento da União Europeia que tem procurado identificar as necessidades dos professores nas competências digitais, por meio da elaboração de instrumentos de avaliação e da realização de relatórios que sustentem o trabalho a ser desenvolvido nesta área. De acordo com a informação disponível na sua página online, a investigação nesta área começou em 2005 e foca-se em encontrar resposta para que as TDIC sejam usadas para "repensar (...) a aprendizagem, para inovar a educação e formação e para abordar os novos requisitos de competências (por exemplo, competências digitais), para gerar crescimento, emprego e inclusão social"4 (EU Science Hub, 2018).

${ }^{4}$ Tradução nossa. No original: "rethink (...) learning, for innovating education and training and for addressing new skills requirements (e.g. digital competence) to generate growth, employment and social inclusion”. Disponível em $<$ https://ec.europa.eu/jrc/en/ research-topic/learning-and-skills>. 
Um dos instrumentos mais relevantes que o EU Science Hub produziu para o campo da educação é o DigCompEduCheckIn, relatório que apresenta um quadro europeu comum para as competências digitais dos professores, baseado na premissa de que estes "precisam de um conjunto de competências digitais específicas para a sua profissão, a fim de aproveitar o potencial das tecnologias para melhorar e inovar a educação" (Redecker, 2017, p. 8, tradução nossa). ${ }^{5}$

Para além deste relatório, desenvolveu-se um questionário online, a partir da colaboração de diversos países europeus, que pode ser respondido pelos professores identificando o nível de competência digital em que se encontram e, mais do que apenas elencar um conjunto de competências, fornece aos utilizadores um relatório que permite conhecer, em função das respostas dadas, sugestões para melhorar as práticas que já desenvolvem.

Estes dois documentos, o relatório e a escala de avaliação, configuram-se como excelentes pontos de partida para definir um instrumento de avaliação das competências digitais dos docentes portugueses, identificando o seu nível de proficiência, e a partir daí apresentar propostas formativas para evoluir para um nível diferente.

Vejam-se, em seguida, as seis áreas de competências abordadas na escala e respetivas subcategorias (Tabela 1).

Tabela 1. DigCompEduCheckIn - questionário de autoavaliação sobre competências digitais. ${ }^{6}$

\begin{tabular}{|l|l|l|l|l|l|}
\hline $\begin{array}{l}\text { Área 1: En- } \\
\text { volvimento }\end{array}$ & $\begin{array}{l}\text { Uso diferen- } \\
\text { tes canais de }\end{array}$ & $\begin{array}{l}\text { Uso tecnolo- } \\
\text { gias e recursos }\end{array}$ & $\begin{array}{l}\text { Desenvolvo } \\
\text { continuamen- }\end{array}$ & $\begin{array}{l}\text { Participo } \\
\text { de oportu- }\end{array}$ & \\
nal & comunicação & digitais para & te o meu uso & nidades de & \\
& para diferentes & trabalhar com & de ferramen- & formação & \\
& objetivos & $\begin{array}{l}\text { colegas dentro } \\
\text { e fora da minha } \\
\text { instituição }\end{array}$ & & & \\
& & & & \\
& & & & \\
\hline
\end{tabular}

5 No original: "need a set of digital competences specific to their profession in order to be able to seize the potential of digital technologies for enhancing and innovating education".

${ }^{6}$ Este inquérito encontra-se, neste momento, em fase de testes e em breve será disponibilizado, em diferentes línguas, a docentes de toda a Europa. No espaço do inquérito os 


\begin{tabular}{|c|c|c|c|c|}
\hline $\begin{array}{l}\text { Área 2: } \\
\text { Tecno- } \\
\text { logias e } \\
\text { Recursos } \\
\text { digitais }\end{array}$ & $\begin{array}{l}\text { Procuro diferen- } \\
\text { tes sítios web } \\
\text { e estratégias } \\
\text { para encontrar } \\
\text { e selecionar } \\
\text { recursos educa- } \\
\text { cionais }\end{array}$ & $\begin{array}{l}\text { Crio os meus } \\
\text { próprios recur- } \\
\text { sos digitais e } \\
\text { modifico outros } \\
\text { já existentes } \\
\text { para adaptá- } \\
\text {-los às minhas } \\
\text { necessidades }\end{array}$ & $\begin{array}{l}\text { Utilizo } \\
\text { diferentes } \\
\text { softwares e } \\
\text { mecanismos } \\
\text { de segurança } \\
\text { para proteger } \\
\text { conteúdo } \\
\text { sensível }\end{array}$ & \\
\hline $\begin{array}{l}\text { Área 3: } \\
\text { Ensino e } \\
\text { aprendiza- } \\
\text { gem }\end{array}$ & $\begin{array}{l}\text { Considero } \\
\text { como, quando e } \\
\text { porquê usar tec- } \\
\text { nologias digitais } \\
\text { na sala de aula, } \\
\text { para garantir } \\
\text { que elas sejam } \\
\text { usadas com } \\
\text { valor acrescen- } \\
\text { tado }\end{array}$ & $\begin{array}{l}\text { Monitorizo a } \\
\text { atividade dos } \\
\text { meus estudan- } \\
\text { tes nos am- } \\
\text { bientes digitais } \\
\text { colaborativos } \\
\text { que usamos }\end{array}$ & $\begin{array}{l}\text { Quando } \\
\text { os meus } \\
\text { estudantes } \\
\text { trabalham em } \\
\text { grupo, usam } \\
\text { tecnologias } \\
\text { digitais } \\
\text { para gerar e } \\
\text { documentar } \\
\text { os dados que } \\
\text { apresentam }\end{array}$ & $\begin{array}{l}\text { Uso tecnolo- } \\
\text { gias digitais } \\
\text { para permi- } \\
\text { tir que os } \\
\text { estudantes } \\
\text { planifiquem, } \\
\text { documen- } \\
\text { tem e moni- } \\
\text { torizem as } \\
\text { suas apren- } \\
\text { dizagens } \\
\text { de forma } \\
\text { autónoma }\end{array}$ \\
\hline $\begin{array}{l}\text { Área 4: } \\
\text { Avaliação }\end{array}$ & $\begin{array}{l}\text { Uso ferramentas } \\
\text { de avaliação } \\
\text { digital, ou } \\
\text { testes e jogos, } \\
\text { para verificar } \\
\text { o progresso do } \\
\text { estudante e for- } \\
\text { necer feedback } \\
\text { mais eficiente }\end{array}$ & $\begin{array}{l}\text { Analiso a } \\
\text { informação } \\
\text { disponível } \\
\text { regularmente } \\
\text { para identificar } \\
\text { os estudantes } \\
\text { que precisam } \\
\text { de apoio adi- } \\
\text { cional }\end{array}$ & $\begin{array}{l}\text { Uso as tecno- } \\
\text { logias digitais } \\
\text { para fornecer } \\
\text { feedback } \\
\text { efetivo }\end{array}$ & \\
\hline
\end{tabular}

autores deste indicam que "Esta ferramenta de autoavaliação baseia-se no Quadro Europeu de Competências Digitais para Educadores. O DigCompEdu é um modelo de competências para professores de todos os níveis de ensino, desde o jardim de infância até o ensino superior e educação de adultos, incluindo educação especial e contextos de aprendizagem não formal. O DigCompEdu divide as competências digitais dos professores em seis áreas diferentes, num total de 22 competências. O foco do modelo não está nas habilidades técnicas. Em vez disso, a afirmação do modelo é perceber como as tecnologias digitais podem ser usadas para aprimorar e modernizar a educação e a formação. Este inquérito pode dar-lhe, como professor, uma avaliação inicial do seu nível atual de desenvolvimento em habilidades pedagógicas digitais. É composto de 22 questões, uma questão por área de competência DigCompEdu. As opções de resposta estão organizadas de acordo com os níveis de competência. Obviamente, você pode escolher as respostas com base no seu nível de proficiência ou com base nos exemplos que por vezes são dados e que considere mais adequados" (tradução nossa). 


\begin{tabular}{|c|c|c|c|c|c|}
\hline $\begin{array}{l}\text { Área 5: } \\
\text { Capacita- } \\
\text { ção dos } \\
\text { estudantes }\end{array}$ & $\begin{array}{l}\text { Quando crio } \\
\text { tarefas digitais } \\
\text { para os estu- } \\
\text { dantes, consi- } \\
\text { dero e procuro } \\
\text { resolver os } \\
\text { problemas que } \\
\text { possam ter } \\
\text { com o formato } \\
\text { digital }\end{array}$ & $\begin{array}{l}\text { Utilizo tecno- } \\
\text { logias para } \\
\text { promover com- } \\
\text { petências digi- } \\
\text { tais adaptadas } \\
\text { às necessidades } \\
\text { individuais dos } \\
\text { estudantes }\end{array}$ & $\begin{array}{l}\text { Uso tec- } \\
\text { nologias } \\
\text { digitais para } \\
\text { desenvolver } \\
\text { metodologias } \\
\text { ativas }\end{array}$ & & \\
\hline $\begin{array}{l}\text { Área 6: } \\
\text { Promoção } \\
\text { da com- } \\
\text { petência } \\
\text { digital dos } \\
\text { estudantes }\end{array}$ & $\begin{array}{l}\text { Ensino os } \\
\text { estudantes a } \\
\text { saber verificar } \\
\text { se a informação } \\
\text { é confiável e a } \\
\text { identificar infor- } \\
\text { mação errada } \\
\text { ou contraditória } \\
\text { através de notí- } \\
\text { cias falsas }\end{array}$ & $\begin{array}{l}\text { Estabeleço } \\
\text { atividades que } \\
\text { exigem que } \\
\text { os estudantes } \\
\text { usem ferramen- } \\
\text { tas digitais para } \\
\text { comunicar uns } \\
\text { com os outros } \\
\text { ou com um pú- } \\
\text { blico externo }\end{array}$ & $\begin{array}{l}\text { Estabeleço } \\
\text { atividades } \\
\text { de aprendi- } \\
\text { zagem que } \\
\text { implicam a } \\
\text { criação de } \\
\text { conteúdos } \\
\text { digitais }\end{array}$ & $\begin{array}{l}\text { Ensino os } \\
\text { estudantes } \\
\text { a compor- } \\
\text { tarem-se } \\
\text { de forma } \\
\text { segura e } \\
\text { responsável } \\
\text { online }\end{array}$ & $\begin{array}{l}\text { Encorajo } \\
\text { os meus } \\
\text { estudan- } \\
\text { tes a usar } \\
\text { tecno- } \\
\text { logias } \\
\text { digitais } \\
\text { de forma } \\
\text { criativa } \\
\text { para } \\
\text { resolver } \\
\text { proble- } \\
\text { mas con- } \\
\text { cretos }\end{array}$ \\
\hline
\end{tabular}

Fonte: elaboração própria.

Para além disso, é possível articular os identificadores apresentados nesta ferramenta, para reconhecimento das competências digitais, com outro documento, publicado pelo mesmo grupo de trabalho, intitulado "The Digital Competence Framework for Citizens", publicado também em 2017 e que apresenta oito níveis de proficiência digital e exemplos do seu uso, com o objetivo de contribuir para aumentar as competências digitais dos cidadãos em geral.

Ambos os instrumentos são bastante úteis, uma vez que fornecem ao cidadão em geral ou ao professor em particular uma forma de perceber o seu nível de proficiência digital e, a partir daí, aferir que mudanças deve operar para melhorar as suas competências.

No que aos docentes diz respeito, interessa-nos avaliar estas seis áreas de competências, definir aquelas em que os docentes encontram mais ou menos dificuldades e delinear estratégias de atuação adequadas às suas necessida- 
des, quer ao nível da formação contínua de professores, quer mesmo extrapolando estas informações para as adequar às necessidades de um docente ainda em formação inicial.

Um dos aspetos que nos parece mais relevante deste inquérito é que ele não se limita a aferir o grau de utilização per se das tecnologias digitais, mas integra-a numa estratégia alargada de articulação entre o processo de ensino-aprendizagem e a evolução do próprio estudante. Um entendimento de que a própria motivação profissional do docente deverá incluir uma consciencialização de quais serão as suas necessidades no campo da utilização das tecnologias digitais, numa lógica de trabalho integrado entre docente e estudante. $\mathrm{E}$ isso é exatamente o que é preconizado no relatório para atingir a fluência digital. Perante um tipo de saber que tem vindo a evoluir de forma vertiginosa, o fluente digital é aquele que percebe que tem de estar permanentemente atualizado e em formação permanente.

\section{Notas finais}

Ao longo das últimas décadas e fruto, sobretudo, das grandes mudanças que têm ocorrido nos mercados de trabalho, tem-se tornado cada vez mais premente repensar os processos pedagógicos. A Escola hoje enfrenta o desafio de ir além do ensino das competências fundacionais, promovendo o desenvolvimento de outro tipo de competências, transversais, multidimensionais e que promovam comportamentos de ordem superior, assumindo-se como cada vez mais necessária a adoção de novas estratégias e de novas metodologias que promovam práticas pedagógicas da emancipação, nomeadamente com vista ao desenvolvimento das competências para o século 21 (WEF, 2015).

Seguindo esta corrente de pensamento, as tecnologias educativas digitais têm vindo a afirmar-se como instrumentos pedagógicos que podem contribuir para a promoção dessas "novas" competências (Trindade; Moreira, 2017a).

Com a apropriação do potencial das tecnologias, podem obter-se ambientes inovadores, cenários de aprendizagem sustentáveis, em que o digital possa ser, verdadeiramente, uma janela aberta para o mundo do conhecimento. Porém, para que isto seja uma realidade, é cada vez mais 
necessário que os docentes (para além dos estudantes) sejam capazes de reconhecer o valor destes recursos e, sobretudo, de identificar de que forma podem evoluir, "crescer" digitalmente e acrescentar valor aos seus processos educacionais.

É nesse sentido que entendemos que os recursos que vêm sendo criados pelo $E U$ Science $H u b$ são instrumentos de avaliação muito válidos para a melhoria dos processos educativos. Com instrumentos como o DigCompEdu CheckIn, encontra-se um ótimo ponto de partida para avaliar o nível de proficiência digital dos docentes, criando a partir daí mecanismos de formação inicial e contínua, para ultrapassar as "barreiras" digitais que o corpo docente pode ainda encontrar atualmente.

\section{Referências bibliográficas}

BEETHAM, H.; SHARPE, R. - Rethinking pedagogy for a digital age: designing and delivering e-learning. Nova Iorque: Routledge, 2007. ISBN 978-0415408745.

BRIGGS, C.; MAKICE, K. - Digital Fluency: building success in the digital age. s.1.: SociaLens, 2012. ISBN 978-0-615-64294-9.

CARretero, S.; VUORIKARI, R.; PUNIE, Y. - The Digital Competence Framework for Citizens With eight proficiency levels and examples of use [Em linha]. Luxembourg: Publications Office of the European Union, 2017. [Consult. 30 Abr. 2018]. Disponível em WWW: <URL: http://publications.jrc.ec.europa.eu/repository/handle/ JRC106281>. DOI 10.2760/38842.

EU SCIENCE HUB - Learning and Skills for the Digital Era [Em linha]. [Consult. 29 Abr. 2018]. Disponível em WWW: <URL: https://ec.europa.eu/jrc/en/research-topic/ learning-and-skills $>$.

Figueiredo, A. D. - Por uma escola com futuro... para além do digital. Nova Ágora Revista. 5 (2016) 19-21.

FLORIDI, L. (Ed.) - The Onlife Manifesto: being buman in a byperconnected era. s.1.: Springer Open, 2015. ISBN 978-3-319-04092-9.

KOELHLER, M. J.; MISHRA, P. - Introducing TPCK. In The handbook of technological pedagogical content knowledge (TPCK) for educators. Nova Iorque: Routledge, 2008. ISBN 978-0-8058-6355-0. p. 3-29. 
LeE, M.; Mcloughlin, C. - Teaching and learning in the Web 2.0 era: Empowering students through learner-generated content. International Journal of Instructional Technology and Distance Learning. ISSN 1550-6908. 4:10 (2007) 21-34.

MARTINS, G. d'O. (Coord.) - Perfil dos alunos à saída da escolaridade obrigatória. Lisboa: Ministério da Educação, 2017. ISBN 978-972-742-416-0.

MiShrA, P.; KOEHLER, M. L. - Technological Pedagogical Content Knowledge: A framework for teacher knowledge. Teachers College Record. ISSN 0161-4681. 108:6 (2006) 1017-1054.

NRC (National Research Council) - Being fluent with information technology. Washington: National Academy Press, 1999. ISBN 978-0309063999.

OZAN, O.; KESIM, M. - Rethinking scaffolding in mobile connectivist learning environments. In BERGE, Z.; MUILENBURG, L. (Eds.) - Handbook of mobile education. Nova Iorque: Routledge, 2013. ISBN 978-0415503693. p. 166-175.

REDECKER, C. - European Framework for the Digital Competence of Educators (DigCom$p E d u$ ) [Em linha]. Luxemburgo: Publications Office of the European Union, 2017. [Consult. 30 Abr. 2018]. Disponível na Internet: <URL: https://publications.europa. eu/en/publication-detail/-/publication/fcc33b68-d581-11e7-a5b9-01aa75ed71a1/ language-en>. DOI 10.2760/159770.

SCHLEMMER, E.; BACKES, L. - Learning in metaverses: co-existing in real virtuality. Hershey: IGI Global, 2015. ISBN 978-1466663510.

Trindade, S. D.; MOREIRA, J. A. - Competências de Aprendizagem e Tecnologias Digitais no Ensino Superior. In MOREIRA, J. A.; VIEIRA, C. P. (Coord.) - eLearning no Ensino Superior. Coimbra: CINEP, 2017a. ISBN 978-989-99463-5-4. p. 99-116.

_ A Emergência do Mobile Learning e os Novos Desafios Formativos para a Docência em Rede. In TORRES, P. (Org.) - Redes e mídias sociais. Curitiba: APPRIS Editora, 2017b. ISBN 978-8581926384. p. 41-57.

_ Ecologia de aprendizagem. In MILL, D. (Org.) - Dicionário crítico de educação e tecnologias e educação a distância. Campinas: Papirus, 2018. ISBN 9788544902950. p. 192-194.

UN - United Nations - Transforming our world: the 2030 Agenda for sustainable development [Em linha] 2015. [Consult. 26 Mar. 2018]. Disponível na Internet: <URL: https://sustainabledevelopment.un.org/post2015/transformingourworld/ publication>. 
WANG, E.; MYERS, M. D.; SUNDARAM, D. - Digital natives and digital immigrants: towards a model of digital fluency. ECIS 2012, 39 - ECIS 2012 Proceedings [Em linha]. 2012. [Consult. 08 Abr. 2018]. Disponível em WWW: <URL: http://aisel.ais net.org/ecis2012/39>.

WEF - World Economic Forum - New Vision for Education: Unlocking the Potential of Technology. Cologny/Geneva: World Economic Forum, 2015. 